

\title{
Políticas Públicas no Turismo sob a ótica da Complexidade: reflexões sobre interações entre aspectos públicos e privados
}

Public Policies in Tourism into the perspective of Complexity: reflections about interactions between public and private aspects

\author{
Graziele Junia Pereira Vilela ${ }^{1}$ \\ Helena Araújo Costa ${ }^{2}$
}

\footnotetext{
${ }^{1}$ Mestranda em Turismo pela Universidade de Brasília. Graduada no curso superior de Turismo na Pontifícia Universidade Católica de Minas Gerais, pós-graduada em Gestão Estratégia em Sustentabilidade e Responsabilidade Social e em Gestão Estratégica em Projetos pelo Centro Universitário UNA. Atuou durante cinco anos na Secretaria de Estado de Turismo de Minas Gerais, sendo os dois últimos como Superintendente de Estruturas do Turismo. Durante um ano foi consultora de turismo na elaboração de planos diretores de turismo de três cidades do interior de São Paulo: Águas da Prata, Caconde e Ilha Solteira. Coordenadora Nacional de Turismo de Sol e Praia e Turismo Cultural do Sebrae desde junho de 2015. Email: grazielejunia@yahoo.com.br
}

2 Professora Adjunta IV do Departamento de Administração da Universidade de Brasília (UnB). Atua nos bacharelado em Administração, Turismo e no Mestrado em Turismo da UnB. É Doutora em Desenvolvimento Sustentável, mestre em Turismo e Hotelaria e Bacharel em Administração. É líder do Laboratório de Estudos em Turismo e Sustentabilidade (LETS/UnB). Foi Assessora Especial do Ministro do Turismo Vinicius Lages no período de 2014 a 2015. Atua internacionalmente como pesquisadora convidada junto ao ao International Center for Responsible Tourism (ICRT, Reino Unido) e à Universidade de Aveiro (Portugal). Dedica-se ao estudo do turismo com foco sobre os seguintes temas: competitividade, sustentabilidade, relações sociais de cooperação e conflito, redes de pequenas empresas do setor e políticas públicas. É membro da comissão julgadora do Prêmio Braztoa de Sustentabilidade em Turismo desde 2014. Publicou 29 artigos em periódicos nacionais e internacionais de renome, bem como 9 capítulos de livros. Participou como palestrante em eventos comerciais e governamentais do turismo, como em eventos científicos nos quais publicou 36 trabalhos completos. Publicou o livro Destinos do turismo: percursos para a sustentabilidade (Ed. FGV, 2013) e é organizadora de Turismo, áreas protegidas e inclusão social: diálogos entre saberes e fazeres (Ed. Folio, 2015). É editora associada da revista Estudios y Perspectivas en Turismo (A2, Argentina) e parecerista ad hoc de agências de fomento e de revistas científicas em Administração e Turismo. Atualmente está finalizando, como organizadora, o livro ?Turismo e Sustentabilidade: verso e reverso?, que será lançado em 2018. Email: helenacosta@unb.br 
O presente artigo ensaístico tem como tema a complexidade no turismo e em suas políticas públicas, apresentando uma reflexão acerca do modo como elas interagem, em nível municipal, com outras duas variáveis do universo privado: capacidade empresarial dos destinos turísticos e o desempenho econômico dos pequenos negócios da cadeia produtiva do turismo. Nesse sentido, a construção teórica propõe uma reflexão sobre o turismo como fenômeno complexo, a evolução de sua representação enquanto sistema aberto e possíveis interações entre seus componentes. O que permitiu elaborar um mapa mental no qual se evidencia que as políticas públicas partem de um contexto maior, que envolve as conjunturas políticas, econômicas e sociais dos destinos turísticos. Constata-se então uma rede de interações mútuas entre as variáveis analisadas, próprias da complexidade, em que as políticas públicas não apenas influenciam, mas também sofrem influências de características privadas do turismo que ocorre em dado território.

Palavras chave: Turismo. Sistema Complexo. Políticas Públicas. Capacidade Empresarial. Desempenho Econômico.

\section{ABSTRACT}

This essay article has as its theme the complexity of tourism and its public policies, presenting a reflection about how they interact, at the municipal level, with two other variables of the private universe: business capacity of tourism destinations and the economic performance of small business of the tourism production chain. In this sense, the theoretical construction proposes a reflection on tourism as a complex phenomenon, the evolution of its representation as an open system and possible interactions among its components. This allowed the elaboration of a mental map in which it is evident that the public policies depart from a larger context, which involves the political, economic and social conjunctures of the tourist destinations. A network of mutual interactions between the analyzed variables, typical of complexity, is observed, where public policies not only influence but also suffer influences of private tourism characteristics that occur in each territory.

Key-Words: Tourism. Complex System. Public Policies. Business Capacity. Economic Performance.

\section{INTRODUÇÃO}

Desde o início do olhar para políticas públicas enquanto ciência, em meados do século XX nos EUA, diversos pensadores empreendem a busca por conceituar o termo, definir seu escopo, entender sua dinâmica, entre outros aspectos desta atuação governamental (SOUZA, 2006). Contudo tal tarefa não é das mais fáceis, como afirma Saravia (2006) ao relatar a sensação de "desordem" que atingiria os cidadãos e também os atores administrativos e políticos, fruto da complexidade e da aparente não governabilidade das políticas públicas. Para ele, nem mesmo os aparatos mais tecnológicos disponíveis seriam capazes de descrever os processos das políticas públicas em sua totalidade. 
Nesse contexto, para o presente artigo optou-se por adotar os pensamentos que abordam as políticas públicas sob a ótica da complexidade. Sendo assim, o conceito central em que o texto se apoia é o de políticas públicas enquanto o fluxo de decisões e o conjunto de ações concretas realizadas pelo poder público para influenciar determinado comportamento, que pode ser individual, coletivo ou até mesmo organizacional, para alcançar os resultados desejáveis (HALL e JENKIS, 2004; SARAVIA, 2006; SOUZA, 2006; RODRIGUES, 2010; RAND, 2015).

O interesse por aproximar a lógica da complexidade, a partir da ótica de Morin (2011), da discussão das políticas públicas pode ser explicado pelo fato de que elas, em função das interações entre os diversos componentes, não são lineares e não seguem a lógica simplista de causa e efeito (FURTADO; SAKOWSKI; TÓVOLLI, 2015), assim como os próprios sistemas de turismo, considerados também essencialmente complexos (BAGGIO, 2008; SCOTT; BAGGIO; COOPER, 2008; COSTA; SOUTO-MAIOR, 2006; MOESCH; BENI, 2015). Portanto, devem ser levadas em consideração as múltiplas causalidades, até mesmo os efeitos não previsíveis, no comportamento a ser influenciado pelas políticas públicas em análise (FURTADO; SAKOWSKI; TÓVOLLI, 2015).

Na proposição de análise deste artigo, a complexidade permeia a reflexão ao tratar das interações mútuas entre três variáveis presentes nos sistemas de turismo: Políticas Públicas, Capacidade Empresarial dos Destinos Turísticos e Desempenho Econômico dos Pequenos Negócios da Cadeia Produtiva do Turismo. Neste ensaio, entende-se a capacidade empresarial dos destinos turísticos como as características desses destinos que favorecem a geração de negócios (MTUR, 2015), enquanto o desempenho econômico dos pequenos negócios equivale aos resultados econômicos e financeiros destes empreendimentos (SEBRAE, 2015). Assim, esta reflexão é motivada pela busca pela compreensão de que forma as políticas públicas de turismo interagem com aspectos do ambiente de negócios do turismo, mote de uma pesquisa mais ampla a qual este trabalho se integra.

Acerca do tema deste trabalho, pode-se observar que diferentes autores discutem como as políticas públicas influenciam outras variáveis, como o mercado turístico (LOHMANN; PANOSSO NETTO, 2008; THURIK, 2008; MTUR, 2015), sendo esta visão a mais recorrente. Em alguma medida, foram encontrados autores que entendem que as políticas públicas também são influenciadas por outras variáveis, como a própria conjuntura política 
(JENKINS; HENRY, 1982; FAYOS-SOLÁ, 1996; HALL; JENKINS, 2004; SOLHA, 2004; LOHMANN; PANOSSO NETTO, 2008).

Isto posto, o presente artigo inicia uma discussão sobre uma das lacunas atuais das pesquisas de turismo: as interações mútuas entre as políticas públicas e as diferentes variáveis que integram o sistema turístico. Essa preocupação encontra fundamento nas considerações de Baggio (2008), que indica a importância e, em contrapartida, a escassez de pesquisas em turismo que avancem na consideração da complexidade, não-linearidade, riscos e incertezas existentes nos sistemas de turismo. Lohmann e Panosso Netto (2008) são mais específicos e afirmam que, em função da complexidade das relações do governo com o turismo, "[...] as pesquisas científicas deveriam discutir como e de que forma as ações governamentais e o próprio governo influenciam e impactam na atividade turística" (LOHMANN; PANOSSO NETTO, 2008, p. 123). É recorrente na literatura a visão de que o desempenho da cadeia produtiva ${ }^{3}$ do setor turístico é fortemente influenciado pelas políticas públicas (LOHMANN; PANOSSO NETTO, 2008; THURIK, 2008; MTUR, 2015). Por outro lado, percebeu-se que as teorias que defendem que as políticas públicas também são influenciadas por outras variáveis, com uma interação de mão dupla assim como propõe a Teoria da Complexidade (MORIN, 2011), são ainda limitados. Sobre essa carência, Lohmann e Panosso Netto (2008) apontam que deveriam existir estudos que também se preocupassem em como o turismo influencia as ações governamentais a fim de analisar um tecido de interconexões mais denso.

A fim de contribuir com esta finalidade, esse artigo está estruturado em três partes, além desta introdução. Na seção 1, apresenta um quadro referencial de conceitos acerca de sistemas complexos aplicados ao turismo e às políticas públicas. Então, a partir dos autores apresentados, oferece um mapa mental que ilustra a reflexão na seção 2. Por fim, seguemse as considerações finais, as limitações do trabalho e a proposta para estudos futuros.

\section{SISTEMAS COMPLEXOS: CONTRIBUIÇÕES PARA PENSAR O TURISMO E AS POLÍTICAS PÚBLICAS}

As primeiras aplicações da análise sistêmica nos fenômenos sociais tiveram seu início nos estudos de Bertalanffy sobre biologia, na década de 1930. E o que ela ainda retratava

\footnotetext{
${ }^{3}$ Para Costa e Souto-Maior (2006), a cadeia produtiva pode ser "[...] entendida como o conjunto de entes privados que compõem o setor [...]. A cadeia produtiva está mais relacionada com a produção, com os canais de distribuição logística e com contratos formais para essas atividades" (COSTA e SOUTO-MAIOR, 2006, p. 8).
} 
era um sistema simples com entradas, saídas e feedback. Apesar de útil para a época, a visão demonstrava fragilidades, já que os sistemas eram fechados, considerados de forma isolada, descolados de seu ambiente, e, supostamente, apresentavam apenas relações lineares (COSTA; SOUTO-MAIOR, 2006). A Teoria da Complexidade (MORIN, 2011) veio para romper com essa visão e, a partir da noção de interação e relacionamento entre os diversos componentes de um sistema e o ambiente que o circunda, contribuiu para um melhor entendimento sobre a dinâmica do turismo (COSTA; SOUTO-MAIOR, 2006).

Nesse contexto, para alguns autores (MOESCH; BENI, 2015; GUILARDUCCI; FRATUCCI, 2016), o estudo sobre sistemas complexos é inerente ao do turismo e passa pela compreensão de suas características/propriedades, que serão apresentadas na sequência.

Os sistemas complexos são abertos, marcados pela dinamicidade, não linearidade e abrangência de um grande número de interações. A não linearidade significa dizer que as saídas podem não ser proporcionais às entradas ou até mesmo não apresentarem apenas uma interação unidirecional. Nesse cenário, a noção de inputs e outputs não tem aplicabilidade (FURTADO; SAKOWSKI; TÓVOLLI, 2015). Observa-se que esse conjunto de características auxilia na diferenciação dos sistemas simples que, conforme explicado por Costa e Souto-Maior (2006), são fechados, sem interações com o ambiente e com relações lineares.

Outro ponto abordado por Furtado, Sakowski e Tóvolli (2015) é o comportamento complexo dos sistemas, que não pode ser deduzido pela forma analítica ex-ante ${ }^{4}$, já que é de difícil previsibilidade em função de sua propriedade emergente. A difícil previsibilidade se deve, principalmente, à ausência de um controlador central e à capacidade dos sistemas complexos se auto organizarem, podendo atingir diferentes e múltiplos estados (FUENTES, 2015). Essa dificuldade pode ser minimizada a partir da compreensão dos gestores que, apesar de não ser possível ter um controle central, enquanto atores do sistema eles tem a possibilidade de influenciá-lo. E essa influência deve ocorrer em suas propriedades, tais como: a interdependência dos componentes/agentes, a conectividade e adaptabilidade (MUELLER, 2015).

Ainda sobre o comportamento emergente, Sichman (2015) identifica o que ele classifica como emergência de segunda ordem. Para o autor, o comportamento individual cria padrões em nível global, que podem permanecer mesmo com a saída do indivíduo. Isso

\footnotetext{
${ }^{4}$ Baseada em prognósticos ou suposições.
} 
acontece porque os demais agentes do sistema reconhecem o comportamento e se apropriam dele como parte da realidade social. Assim, com a entrada de novos indivíduos, o comportamento será transmitido do nível global para o individual, dando origem a emergência de segunda ordem. Outra autora que reforça a importância de se estudar as interações entre componentes/agentes dos sistemas complexos é Tessone (2015). Na visão da estudiosa, por mais simples que sejam essas interações, elas que produzem o comportamento complexo. Por isso, compreender como ocorre esse processo interativo é chave para a compreensão da dinâmica do sistema turístico.

Já Beni (2007) alerta que o turismo não é uma manifestação isolada, havendo relação e interdependência entre diversas áreas, tais como o meio ambiente natural, cultural, a vida pessoal e a organização social. Nesse contexto, vale destacar que não são apenas as políticas públicas de turismo que influenciam o setor. O êxito do turismo depende também do desempenho de outros setores, tanto dos econômicos como dos sociais, que podem ter políticas públicas específicas. E as intervenções governamentais que deveriam preceder as demais no turismo seriam àquelas relacionadas à infraestrutura, responsável por suportar o recebimento do fluxo turístico. Contudo, essas políticas públicas específicas de outros setores não necessariamente são pensadas em função do turismo, apesar de poderem trazer algum tipo de rebatimento (VIEIRA, 2013). Fato que evidencia um distanciamento do planejamento público da abordagem sistêmica.

Estudos sobre as interações que ocorrem nas políticas públicas são centrais nos sistemas complexos (FURTADO; SAKOWSKI; TÓVOLLI, 2015). Nesse contexto, ao analisar as políticas públicas pela abordagem sistêmica, os pesquisadores dão um importante passo para compreender como os sistemas complexos são afetados por elas. Isso porque, conforme explicam Furtado, Sakowski e Tóvolli (2015), existem pontos de alavancagem dentro dos sistemas complexos que, ao serem acionados pelas políticas públicas, podem alterar a dinâmica vigente para àquela desejada. Considerando as principais características elencadas, conclui-se que as políticas públicas podem ser mais assertivas se forem orientadas para:

i) aprimorar a resiliência do sistema e reduzir suas vulnerabilidades;

ii) evitar (ou promover) perigosos (ou positivos) pontos críticos; e

iii) identificar os principais intervenientes em uma rede que possam promover (ou prevenir) mudanças no sistema. Isso significa que políticas públicas devem tentar compreender os mecanismos subjacentes do 
Partindo, então, da noção de turismo enquanto um sistema complexo, no qual há interações constantes com o ambiente e com os elementos que o compõem (MOESCH, 2004; COSTA e SOUTO-MAIOR, 2006; BENI, 2007; RITCHIE e CROUCH, 2010), faz-se importante refletir como ocorrem estas interações, afinal a complexidade também é um atributo encontrado nos sistemas de turismo, que podem ser entendidos sob diferentes perspectivas.

Beni (1998), por exemplo, inicialmente caracterizou o Sistur como um sistema aberto, composto por subsistemas, que realiza trocas com o ambiente que o circunda, sendo interdependente e nunca autossuficiente. Apesar de apresentar a noção de relações, a representação original do Sistur ainda era baseada em um sistema simples, com a presença de inputs e outputs e uma lógica linear, que foi sendo complementada e revisitada. Então, em 2015, Moesch e Beni (2015) apresentaram uma revisão do Sistur a partir da Teoria da Complexidade (MORIN, 2011). Segundo os autores os modelos sistêmicos, até então apresentados, incluindo a proposta original do Sistur, são limitados, diante da dinâmica das práticas do turismo. Sendo assim, o "novo" Sistur assume o formato de um holograma no qual os subsistemas passam a ser considerados como objetos que caminhariam para um equilíbrio. E esse equilíbrio para o fenômeno turístico seriam os clusters.

Já o modelo de Stear (1987, 2003a, b), de acordo com Costa e Souto-Maior (2006), promove um considerável avanço pelo fato de englobar diversas características de um sistema complexo ao apresentar uma grande "amplitude de elementos e ambientes, múltiplas relações possíveis entre eles e a qualificação dos fluxos existentes entre as entidades e delas com seus ambientes" (COSTA e SOUTO-MAIOR, 2006, p. 5). Destaca-se que a fonte de inspiração para o sistema de Stear $(1987,2003 a$, b) são os estudos de Leiper $(1979,2003)$, que representavam um sistema turístico a partir do fluxo geográfico dos turistas, elemento central que alavanca a dinâmica do turismo (COSTA; SOUTO-MAIOR, 2006). 
CENÁRIO, Brasília, V.5, n.9 | 91-99 | Dez. 2017 | p. 91

\section{POLÍTICAS PÚBLICAS E INTERAÇÕES COMPLEXAS NO FENÔMENO TURÍSTICO: uma proposta de mapa mental}

Quando se tratam das possíveis interações entre variáveis que integram o sistema turístico, na literatura são encontrados diferentes autores que se propõem a discutir o tema. Ao trazer as políticas públicas para o centro do debate, a visão mais recorrente é aquela de que elas influenciam as demais variáveis do sistema turístico, ou seja, de que a direcionalidade de influências parte das políticas públicas, sem prever retroações de outras variáveis sobre esta. Exemplos desta visão podem ser encontrados em Lohmann e Panosso Netto (2008), ao explicarem que políticas e ações governamentais podem tanto estimular quanto inibir o desenvolvimento do turismo. Seguindo esse mesmo raciocínio Thurik (2008) identificou que nas economias classificadas como empreendedoras, o governo tem papel central ao definir políticas públicas de estímulo ao desenvolvimento dos negócios, principalmente em âmbito local. Já Souza (2006) afirma ser inevitável que as teorias expliquem as relações com o Estado, a própria política, a economia e a sociedade, já que as políticas públicas influenciam esses elementos. O MTur (2015), por sua vez, considera que o desempenho econômico do turismo pode ser determinado pelo desempenho individual das empresas e que este é influenciado tanto por fatores internos quanto externos, como as políticas públicas.

Já a outra via das interações, ou seja, parte das retroações deste sistema, que pode ser vista como a influência que as demais variáveis teriam sobre as políticas públicas, é abordada por Jenkins e Henry (1982). Os autores consideram que o envolvimento governamental reflete a importância do setor turístico na economia dos países. Sendo assim, quanto maior o poder econômico do turismo, mais chances dos destinos terem políticas públicas específicas, como se elas fossem reativas a um setor que é reconhecido como economicamente forte. Ou seja, não somente as políticas públicas atuariam sobre o desempenho econômico do turismo, como também este exerceria, simultaneamente, influência sobre o desenho das primeiras. Solha (2004) colabora com a visão dos autores e afirma que, apenas quando o turismo adquire robustez econômica, surgem as preocupações em se estabelecer políticas públicas. Ou quando o turismo começa a causar transtornos.

Fayos-Solá (1996), por sua vez, soma a este debate ao apontar que a ação governamental no turismo acompanha o que ele chama de paradigma empresarial. Se esse 
paradigma está voltado para a competitividade, por exemplo, os objetivos das políticas públicas são direcionados para criação e manutenção de uma estrutura que permita a competitividade empresarial. E, por último, Hall e Jenkins (2004) acreditam que a atividade política é influenciada e, até mesmo, constituída, pelas características sociais e econômicas das sociedades, assim como pela estrutura do governo e do sistema político.

Diante dos aspectos conceituais apresentados, entende-se que em grande parte, essas influências são reflexos de algumas configurações das políticas públicas, como a definição de papéis e o compartilhamento de responsabilidades entre o setor público e o privado. Nesse contexto, a de se destacar o que Solha (2004) considera como os dois principais papéis/atribuições das Políticas Públicas: ser meio para obter resultados mais eficazes e ser estratégia para um desenvolvimento equilibrado, mesclando assim funções estratégicas e operacionais. A autora complementa e defende que as Políticas Públicas devem "[...] funcionar tanto no estímulo e no controle direto do desenvolvimento do turismo, como também preocupar-se com a proteção dos interesses da sociedade" (SOLHA, 2004, p. 13). Já para Lickorisch e Jenkins (2000) um dos possíveis papéis do estado no turismo seria o de oferecer um ambiente propício para o setor privado, por meio do apoio legal e da infraestrutura.

Ainda sobre as atribuições do poder público, Solha (2004) destaca em seu texto que alguns autores, como Lickorisch (1994) e Cooper et al (2000), abordam o tema sob a perspectiva mais técnica do gerenciamento. A partir dessa ótica, poderiam ser citadas duas principais categorias de atribuições para o poder público: gerenciamento de oferta e custos e gerenciamento de demanda e receita. Para Solha (2004) essa atuação mais técnica pode contribuir para os resultados comerciais do turismo, entretanto, desconsideram "[...] as influências e a importância das interferências políticas e da participação da comunidade" (SOLHA, 2004, p. 29). Essa reflexão complementa a visão de Tessone (2015) que afirma que por mais simples que sejam as interações, elas que produzem o comportamento complexo dos sistemas. Sendo assim, ao se afastar de influências políticas, as atribuições técnicas perdem contato com o que é ou pode vir a ser o comportamento do sistema turístico.

Nesse tecido de interconexões, a atividade política é influenciada e, até mesmo, constituída, pelas características sociais e econômicas das sociedades, assim como pela estrutura do governo e do sistema político. Além da influência de ideologias políticas, as quais elas também estão sujeitas (HALL; JENKIS, 2004). 
Outro fator que chama a atenção é a imprevisibilidade do interesse do poder público no turismo, o que impacta na definição das orientações para o setor privado, causando desequilíbrio nas relações (LOHMANN; PANOSSO NETTO, 2008). As políticas e ações governamentais podem tanto estimular quanto inibir o desenvolvimento do turismo, dependendo, muitas vezes, do momento político em que se encontram os territórios (LOHMANN; PANOSSO NETTO, 2008). Além da influência da conjuntura que as Políticas Públicas sofrem, Solha (2004) considera que a importância que o turismo adquire também é determinante para o tipo de atuação do poder público:

No turismo as preocupações em se estabelecer políticas para o setor só aparecem quando este adquire importância econômica, ou quando começa a causar transtornos. Além disso, caracteriza-se pela espontaneidade, com pouco ou nenhum controle de seu desenvolvimento, obedecendo apenas à lei de mercado (SOLHA, 2004, pp. 9-10).

Observa-se que quando outros setores econômicos de um país estão passando por dificuldades, as Políticas Públicas são colocadas em pauta, uma vez que o turismo é considerado como uma alternativa rápida para impulsionar a economia. Contudo, geralmente, a intervenção é imediatista e voltada apenas para a entrada de moedas estrangeiras (SOLHA, 2004). Outros autores que apresentam pensamento nessa linha são Jenkins e Henry (1982). Para eles o envolvimento governamental reflete a contribuição do setor turístico na economia e que os impactos observados nos países anfitriões são de responsabilidade do setor público mais do que do privado. A forma de medir a participação econômica do turismo passa por quatro indicadores: contribuição para o PIB interno e Rendimento Nacional, Receitas de Câmbio, Emprego e Renda Gerada, e Contribuição para as Receitas do Governo (JENKIS; HENRY, 1982). Nesse contexto, os autores citam ainda cinco grandes áreas identificadas nas Políticas Públicas: I) Receitas de Câmbio, II) Investimento Estrangeiro, III) Empregabilidade no Turismo, IV) Política sobre o Uso do Solo, e IV) Transporte Aéreo e Turismo. Chama atenção a conclusão que Jenkins e Henry (1982) chegam. Para eles, apesar do setor público ser responsável pelo planejamento do turismo, e consequentemente de seus efeitos, o privado é que atenderia melhor as mudanças relacionadas aos fatores da demanda turística. Por isso, o governo deveria se envolver apenas em macro objetivos (JENKIS; HENRY, 1982). 
Pensamento similar é apresentado por Fayos-Solá (1996) quando o autor aponta que a ação governamental no turismo acompanha o que ele chama de paradigma empresarial. Se esse paradigma está voltado para a competitividade, por exemplo, os objetivos das políticas públicas são direcionados para a criação e manutenção de uma estrutura que permita a competitividade empresarial. Esse acompanhamento, entretanto, não necessariamente seria de forma harmoniosa, já que o poder público seria obrigado a mudar suas políticas para atender as novas tendências do turismo. Ou seja, haveria uma defasagem entre as políticas públicas e o que de fato acontece no turismo, o que evidencia uma falta de dinamismo na esfera pública. Nesse cenário seria razoável redefinir o conceito tradicional de quem é responsável pela execução das Políticas Públicas. Com essa redefinição, questões estruturais continuariam sob a responsabilidade do poder público. Já aquilo que é ligado à qualidade da oferta, gestão das empresas e dos destinos turísticos poderia ser compartilhado com o privado e setores voluntários (FAYOS-SOLÁ, 1996)

Assentado então na teoria consultada, chega-se à proposição de um mapa mental sobre a existência de interações mútuas entre as variáveis investigadas PP - Políticas Públicas, CEDT - Capacidade Empresarial dos Destinos Turísticos e DEPNT - Desempenho Econômico dos Pequenos Negócios de Turismo:

\section{SISTEMA TURÍSTICO}

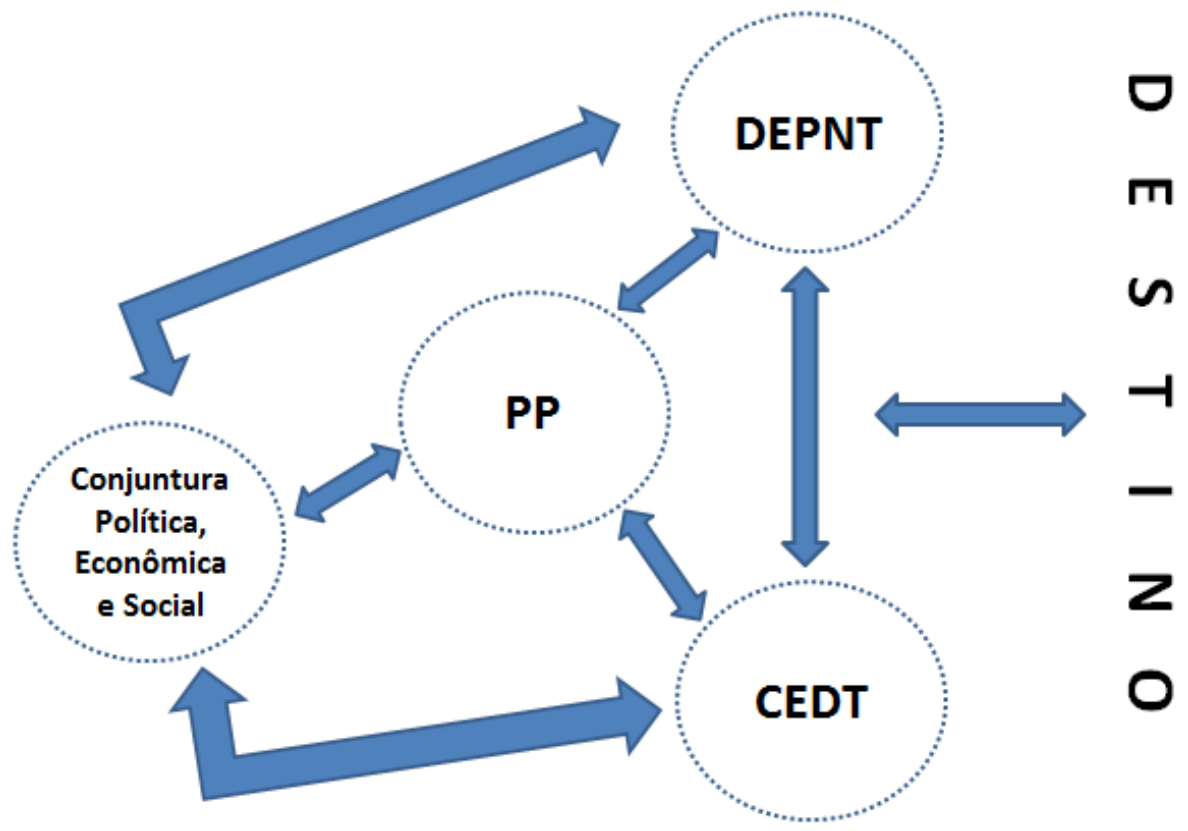

Figura 1 - Mapa Mental das Interações entre as Variáveis Investigadas Fonte: as autoras 
CENÁRIO, Brasília, V.5, n.9 | 95- 99 | Dez. 2017 | p. 95

No mapa proposto, a Conjuntura Política, Econômica e Social aparece tanto como ponto de partida do sistema turístico quanto de chegada, já que, as políticas públicas tanto influenciam o desenvolvimento do turismo quanto são influenciadas por esse contexto maior (HALL; JENKINS, 2004; LOHMANN; PANOSSO NETTO, 2008). E a mesma leitura deve ser feita para o Destino, que recebe influências do conjunto das variáveis assim como as influencia (JENKINS; HENRY, 1982). Na sequência, aparecem as três variáveis que apresentam as interações mútuas: Políticas Públicas, Capacidade Empresarial dos Destinos Turísticos e Desempenho Econômicos dos Pequenos Negócios da Cadeia Produtiva do Turismo. Estas, por sua vez, são produto e produtor da Conjuntura e do Destino (MORIN, 2011). A representação da seta dupla busca evidenciar as referidas interações mútuas que, de acordo com os autores apresentados ao longo do artigo, tendem a ser positivas. Ou seja, quando as políticas públicas são presentes e consistentes, as demais variáveis tenderiam a ter o desempenho impulsionado.

\section{CONSIDERAÇÕES FINAIS}

Este artigo ensaístico teve como objetivo apresentar um mapa mental que representasse a existência de interações mútuas entre três variáveis: Políticas Públicas, Capacidade Empresarial dos Destinos Turísticos e Desempenho Econômico dos Pequenos Negócios da Cadeia Produtiva do Turismo.

Assim, a construção teórica propôs uma reflexão sobre o turismo enquanto fenômeno complexo e a evolução de sua representação como sistema, contemplando interações entre diferentes variáveis, como as destacadas pelo artigo. Ficou então evidenciada pela literatura consultada a aplicabilidade da noção de complexidade tanto ao estudo de políticas públicas quanto ao olhar sobre o turismo como sistema em virtude de algumas características partilhadas por ambos, tais como: (a) a ampla gama de variáveis envolvidas, (b) a consequente multiplicidade de relações entre elas, (c) a falta de linearidade nestas interações, bem como (d) a influencia de ambientes sobre os elementos.

Conforme pôde ser observado, é comum encontrar estudos sobre como as políticas públicas influenciam outras variáveis, olhando para a questão com uma única direção. $E$, em menor escala, a bidirecionalidade de interações e retroações proposta pela Teoria da 
Complexidade (MORIN, 2011) também é apresentada. Ou seja, em alguma medida, existem autores que entendem que as políticas públicas também são influenciadas por outras variáveis, principalmente em contextos nos quais o poderia econômico do turismo é evidenciado. Esse caminho "de mão dupla" de variáveis influenciando as políticas públicas deve ser expandido para além das fronteiras econômicas. No entanto, seria importante compreender para quais aspectos, e os respectivos motivos, os gestores públicos e privados estão mais sensíveis a elaborar políticas.

A aplicação da noção de sistemas complexos à reflexão sobre turismo suas políticas públicas permitiu elaborar um mapa mental no qual se evidenciou que as políticas públicas estão imersas em um contexto maior, que envolve as conjunturas políticas, econômicas e sociais dos destinos turísticos (HALL; JENKINS, 2004 LOHMANN; PANOSSO NETTO, 2008). E que em uma visão aplicada ao turismo, pode-se dizer que elas influenciam, assim como são influenciadas, por características presentes nos destinos - tais como as características conjunturais, as forças de atores sociais, seus jogos de interesses, etc. Os destinos turísticos, ao passo que são produtos das interações de diversas variáveis, também são responsáveis por influenciar as referidas interações, inclusive provocando e moldando as políticas públicas que são desenhadas e implementadas, como elucidaram Jenkins e Henry há mais de 30 anos.

Constata-se então a insuficiência das análises unidirecionais para dar conta da complexidade do turismo, já que a realidade se apresenta em uma rede de interações mútuas entre as variáveis analisadas, em que as políticas públicas não apenas influenciam, mas também sofrem influências de características privadas do turismo que ocorre em dado território.

Ressalta-se que este artigo consiste em um passo inicial de reflexão e que abre espaço para uma verificação empírica acerca das características das interações entre as variáveis aqui exploradas. Caberia para estudos futuros à qualificação de tais relações, analisando como elas ocorrem, se são proporcionais, positivas, negativas ou até mesmo nulas, com a aplicação de métodos quantitativos e qualitativos. Por fim, a representação proposta auxilia no entendimento de que o comportamento do sistema turístico está altamente relacionado com as interações das diversas variáveis que o integram, contribuindo para um olhar mais complexo sobre as políticas públicas de turismo. 


\section{REFERÊNCIAS}

BAGGIO, R. Symptoms of complexity in a tourism system. Tourism Analysis, V. 13, № 1 , 2008, p. 1-20.

BENI, Mario Carlos. Análise Estrutural do Turismo. 1a edição. São Paulo: SENAC, 1998.

Análise Estrutural do Turismo. 13a edição. São Paulo: SENAC, 2007.

COSTA, Helena Araújo; SOUTO-MAIOR, Alice. Sistemas produtivos locais em turismo: relacionamentos estratégicos e aglomeração territorial como vantagens competitivas. Vol. I, № 1,2006, p. 1-22.

FAYOS-SOLÁ, Eduardo. Tourism Policy: a midsummer night's dream? Tourism Management. Vol. 17. № 6, 1996, p. 405-412.

FUENTES, Miguel Angel. Métodos e Metodologias em Sistemas Complexos. In: INSTITUTO DE PESQUISA ECONÔMICA APLICADA - IPEA. Modelagem de Sistemas Complexos para Políticas Públicas. Brasília: IPEA, 2015.

FURTADO, Bernardo Alves; SAKOWSKI, Patrícia Alessandra Morita; e Tóvolli, Marina Haddad. Abordagem de Sistemas Complexos para Políticas Públicas. In: INSTITUTO DE PESQUISA ECONÔMICA APLICADA - IPEA. Modelagem de Sistemas Complexos para Políticas Públicas. Brasília: IPEA, 2015.

GUILARDUCCI, Bruno Campos; FRATUCCl, Aguinaldo Cesar. Teoria dos Sistemas Complexos e Possíveis Aplicações nos Estudos sobre as Políticas Públicas de Turismo. In: Anais do Seminário da ANPTUR, 2016. São Paulo.

HALL, Colin Michael; JENKINS, John. Tourism and Public Policy. In LEW, Alan A.; HALL, Colin Michael; WILLIAMS, Allan M. A Companion to Tourism. Blackwell Publishing: 2004.

JENKINS, Carson L; HENRY, B.M. Government Involvement in Tourism in Developing Countries. Annals of Tourism Research. Vol. 9, 1982, p. 499-521.

LICKORISCH, Leonard J; JENKIS, Carson L. Introdução ao Turismo. Rio de Janeiro: Campus, 2000.

LOHMANN, Guilherme; PANOSSO NETTO, Alexandre. Teoria do Turismo: conceitos, modelos e sistemas. São Paulo: Aleph, 2008.

MINISTÉRIO DO TURISMO. Índice de Competitividade do Turismo Nacional. Relatório Brasil $2008 . \quad$ Disponível em: http://www.turismo.gov.br/sites/default/turismo/o ministerio/publicacoes/downloads pub licacoes/MIOLO 65xdestinosx revisao4set.pdf. Acesso em: 26 de março de 2017.

Brasil 2015. Disponível em: Índice de Competitividade do Turismo Nacional. Relatório 
<http://www.bibliotecas.sebrae.com.br/chronus/ARQUIVOS CHRONUS/bds/bds.nsf/fef94c1 63da070213d455b65b64c794f/\$File/5833.pdf>. Acesso em: 03 de setembro de 2016.

MOESCH, Marutschka Martini. Epistemologia Social do Turismo. São Paulo: ECA/USP, 2004.

MOESCH, Marutschka Martini; BENI, Mario Carlos. Do Discurso da Ciência para a Ciência do Turismo. In: Anais do Seminário da ANPTUR, 2015. São Paulo.

MORIN, Edgar. Introdução ao Pensamento Complexo. Porto Alegre: Sulina, 2011.

MUELLER, Bernardo. Sistemas Complexos em Políticas Públicas no Brasil. In: INSTITUTO DE PESQUISA ECONÔMICA APLICADA - IPEA. Modelagem de Sistemas Complexos para Políticas Públicas. Brasília: IPEA, 2015.

RAND, William. Sistemas Complexos: Conceitos, Literatura, Possibilidades e Limitações. In: INSTITUTO DE PESQUISA ECONÔMICA APLICADA - IPEA. Modelagem de Sistemas Complexos para Políticas Públicas. Brasília: IPEA, 2015.

RITCHIE, J.R. Brent; CROUCH, I. Geoffrey. A Model of Destination Competitiveness/Sustainability: Brazilian Perspectives. Revista de Administração Pública RAP, Rio de Janeiro, 44 (5), 2010.

RODRIGUES, Marta M. Assumpção. Políticas Públicas. São Paulo: PubliFolha, 2010.

SARAVIA, Enrique. Introdução à Teoria da Política Pública. In SARAVIA, Enrique; FERRAREZI, Elisabete (Org.). Políticas Públicas. Brasília: ENAP, 2006.

SCOTT, N.; BAGGIO, R.; C. COOPER (org.). Network analysis and Tourism: from theory to practice. London: Chanel View Publications, 2008.

SERVIÇO BRASILEIRO DE APOIO ÀS MICRO E PEQUENAS EMPRESAS. Perfil Empreendedor. Quem são os Pequenos Negócios? Disponível em: $<$ www.sebrae.com.br/sites/PortalSebrae/estudos pesquisas/quem-sao-os-pequenosnegociosdestaque5,7f4613074c0a3410VgnVCM1000003b74010aRCRD>. Acesso em: 02 de abril de 2017.

SICHMAN, Jaime Simão. Operacionalizando Sistemas Complexos. In: INSTITUTO DE PESQUISA ECONÔMICA APLICADA - IPEA. Modelagem de Sistemas Complexos para Políticas Públicas. Brasília: IPEA, 2015.

SOLHA, Karina Toledo. Órgãos Públicos Estaduais e o Desenvolvimento do Turismo no Brasil. 2004. 168 f. Tese (Doutorado em Ciências da Comunicação) - Escola de Comunicação e Artes, Universidade de São Paulo, 2004.

SOUZA, Celina. Políticas Públicas: Conceitos, Tipologias e Sub-Áreas. V. 18, № 51, 2006, p. $15-20$. 
TESSONE, Claudio J. A Natureza Complexa dos Sistemas Sociais. In: INSTITUTO DE PESQUISA ECONÔMICA APLICADA - IPEA. Modelagem de Sistemas Complexos para Políticas Públicas. Brasília: IPEA, 2015.

THURIK, Roy. Entrepreneurship, Economic Growth and Policy in Emerging Economies. ERIM Report Series Research in Management, 2008. Disponível em: $<$ https://papers.ssrn.com/sol3/papers.cfm?abstract id=1276618>. Acesso em: 05 de janeiro de 2017.

VIEIRA, Daniel Pires. Investimentos, Competitividade e Desenvolvimento em Destinos Indutores do Turismo Brasileiro. 2013. 129 f. Dissertação (Mestrado em Administração) Faculdade de Economia, Administração, Contabilidade e Ciência da Informação e Documentação, Universidade de Brasília, Brasília, 2013. 